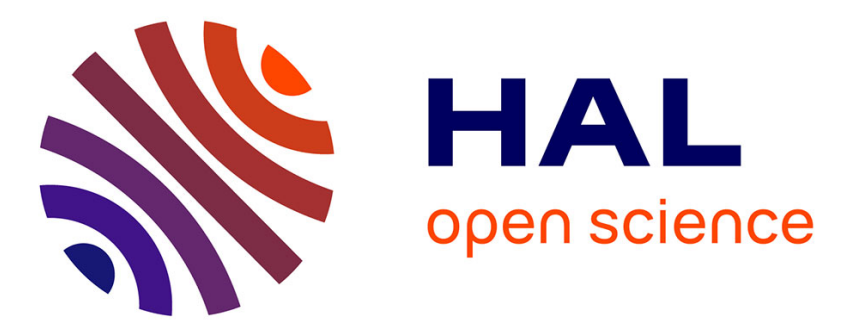

\title{
Study of the lithium insertion-deinsertion mechanism in nanocrystalline $\gamma$-Fe2O3 electrodes by means of electrochemical impedance spectroscopy
}

\author{
Mathieu Quintin, Olivier Devos, Marie-Hélène Delville, Guy Campet
}

\section{- To cite this version:}

Mathieu Quintin, Olivier Devos, Marie-Hélène Delville, Guy Campet. Study of the lithium insertiondeinsertion mechanism in nanocrystalline $\gamma$-Fe2O3 electrodes by means of electrochemical impedance spectroscopy. Electrochimica Acta, 2006, 51 (28), pp.6426-6434. 10.1016/j.electacta.2006.04.027 . hal-00115648

\author{
HAL Id: hal-00115648 \\ https://hal.science/hal-00115648
}

Submitted on 22 Nov 2006

HAL is a multi-disciplinary open access archive for the deposit and dissemination of scientific research documents, whether they are published or not. The documents may come from teaching and research institutions in France or abroad, or from public or private research centers.
L'archive ouverte pluridisciplinaire $\mathbf{H A L}$, est destinée au dépôt et à la diffusion de documents scientifiques de niveau recherche, publiés ou non, émanant des établissements d'enseignement et de recherche français ou étrangers, des laboratoires publics ou privés. 


\title{
STUDY OF THE LITHIUM INSERTION-DEINSERTION MECHANISM IN NANO- CRYSTALLINE $\gamma$-FE $\mathrm{O}_{3}$ ELECTRODES BY MEANS OF ELECTROCHEMICAL IMPEDANCE SPECTROSCOPY
}

\author{
M. Quintin ${ }^{\mathrm{b}}$, O. Devos ${ }^{1 a^{*}}$, M.H. Delville ${ }^{\mathrm{b}}$ and G. Campet \\ ${ }^{a}$ Laboratoire Interfaces et Systèmes Electrochimiques \\ LISE - UPR15 - CNRS, Université Pierre et Marie Curie \\ 4, Place Jussieu, 75252 Paris cedex 05 France
}

${ }^{\mathrm{b}}$ Institut de Chimie de la Matière Condensée de Bordeaux, Université Bordeaux 1

ICMCB - UPR 9048 - CNRS, 87 Avenue du Dr. A. Schweitzer, 33608 Pessac cedex, France

\begin{abstract}
Lithium intercalation hosts are a key point to the energy density of the largely used $\mathrm{LiCoO}_{2}$ (even if of high cost and toxicity) as well as of manganese oxides which have been investigated most extensively. Iron oxides are attractive electrode materials for low-voltage rechargeable lithium batteries from both cost and environmental standpoints. However, search for iron oxides of conventional crystalline structures and micrometer particle sizes as lithium intercalation cathodes, has been greeted with disappointing results. Here, we report on the synthesis, characterizations, electrochemical study and Electrochemical Impedance Spectroscopy (EIS) of a nanocrystalline $\gamma-\mathrm{Fe}_{2} \mathrm{O}_{3}$ that simultaneously exhibits high lithium
\end{abstract}

\footnotetext{
${ }^{1}$ ISE member

*Corresponding author. Tel.: +33.1.44.27. 41.70; fax: +33.1.44.27.40.74

E-mail address: odevos@ccr.jussieu.fr
} 
insertion capacity and good capacity retention upon cycling. These properties reveal thermodynamics of the nanocrystalline material inherently different from those of its microcrystalline counterpart. Moreover, EIS showed that the intercalation process of the lithium ion occurs according to two processes involving first the reduction of the surface $\mathrm{Fe}^{3+}$ with concomitant charge neutralization by $\mathrm{Li}^{+}$ions onto the surface defects of the nanoparticle followed by the reduction of the core $\mathrm{Fe}^{3+}$ with insertion of the $\mathrm{Li}^{+}$deeper in the particle.

\section{Introduction}

Among the transition metal oxides for electrochemistry, binary iron oxides such as $\alpha-\mathrm{Fe}_{2} \mathrm{O}_{3}$, $\mathrm{Fe}_{3} \mathrm{O}_{4}$ and $\gamma-\mathrm{Fe}_{2} \mathrm{O}_{3}$, are among the most attractive materials, by virtue of their environmental affinity, abundance and low price. In spite of such merits, these oxides have been relatively less studied as cathode materials for lithium secondary batteries due to their low electrochemical potential and most significantly to their frustrating cyclability. The poor cyclability performances were, in fact, observed for well crystallized phases and resulted from the irreversible transformation of the corundum/spinel to the disordered rock-salt structure [1, $2,3]$. However, recently, iron oxides with nano-sized particle have been reported to react with lithium in a reversible way [4, 5, 6, 7, 8]. For example, Komaba et al. [9] reported that nanosized $\alpha-\mathrm{Fe}_{2} \mathrm{O}_{3}$ demonstrated a high reversible capacity of $200 \mathrm{mAh} / \mathrm{g}$ and a good cyclability in the potential range 1.5-4.0 V vs. $\mathrm{Li}^{+} / \mathrm{Li}$. Some of us $[10,11,12,13]$, and more recently Kanzaki et al. [14] showed a similar drastic effect on the enhancement of the electrochemical reactivity with lithium for the $\gamma-\mathrm{Fe}_{2} \mathrm{O}_{3}$ variety as the crystallite size is reduced. To account for these observations, we have proposed an electrochemical model which has already been confirmed for many nanosized materials other than binary iron oxides $[12,15,16]$. It highlights the effect of structural defects, predominant at or near the 
nanocrystallite surfaces. A band energy scheme illustrating the model is given in Fig. 1. The nanocrystalline materials present many sub-band-gap states between the conduction band and valence band originating from surface defects (distortion of coordination polyhedron, dangling bonds etc...). The cationic sub-band represents sub-band gap energy states arising from such structural defects. The electron transfer being a fast reaction, the rate limiting step is the induced electrochemical $\mathrm{Li}^{+}$insertion process. It is divided in two steps (process (1), Fig. 1), the first one occurring at/near the grain interface is concomitant to the electron filling of these cationic sub-band gap energy states and maintains the electroneutrality [17]. It leads to a monotonous discharge in the first part of the curve as compared to the well-crystalline homologues. This behaviour corresponds to a regular change of the Fermi-energy level in the electrode without undergoing any significant structural change. This step, also mentioned as "physical grafting" by some authors [15] will be called "surface Li insertion process" all along the paper. The consecutive electrochemical process (2), corresponds to electron injection in the conduction band $\mathrm{CB}$.

Nanocrystalline $\gamma-\mathrm{Fe}_{2} \mathrm{O}_{3}$, has been shown to exhibit an enhanced electrochemical activity in comparison with its microcrystalline homologue, $[13,14]$. However, the mechanism leading to this phenomenon is not yet well established. In order to check the proposed electrochemical model, and the effectiveness of the presence of two electrochemical steps, we investigate in this paper the insertion-deinsertion mechanisms in nanocrystalline $\gamma-\mathrm{Fe}_{2} \mathrm{O}_{3}$ by means of Electrochemical Impedance Spectroscopy (EIS). Its electrochemical activity as a lithium battery cathode and its XRD and TEM analysis are also reported. 


\section{Experimental}

Sample Preparation. The maghemite nanoparticles were prepared following the method developed by Massart et al. $[18,19]$. First, magnetite $\left(\mathrm{Fe}_{3} \mathrm{O}_{4}\right)$ was precipitated by alkalizing an aqueous iron chloride solution containing $\mathrm{Fe}^{2+} / \mathrm{Fe}^{3+}=0.5$ with $\mathrm{NH}_{4} \mathrm{OH}$, leading to a magnetic colloid formation. In this reaction, the base nature, kinetics of reactants addition, concentration, temperature, stirring, precursors purity are all, significant parameters, which determine the product size distribution and phase. In a typical run, $143 \mathrm{ml}$ of $2.21 \mathrm{M} \mathrm{FeCl}_{3}$ aqueous solution (containing $316 \mathrm{mmol} \mathrm{FeCl}_{3}$ ) and $170 \mathrm{ml} 1.5 \mathrm{M} \mathrm{HCl}$ solution with 158 mmol $\mathrm{FeCl}_{2}$ were prepared separately, and mixed with 3.51 of distilled water. The addition of $300 \mathrm{ml}$ of $8.6 \mathrm{M} \mathrm{NH}_{4} \mathrm{OH}$ solution was followed by strong agitation for $15 \mathrm{~min}$. This process gives $\sim 36 \mathrm{~g}$ of $\mathrm{Fe}_{3} \mathrm{O}_{4}$ which is, then, oxidized to the more stable maghemite. The oxide nanoparticle surface is then acidified by replacing the flocculating counter-ions $\mathrm{NH}_{4}{ }^{+}$by nitrate ions $\mathrm{NO}_{3}{ }^{-}$allowing, as well, their superficial oxidation. The final step consists of addition of the particles to a ferric nitrate solution at boiling temperature. The product was washed 4 times with water and acetone and dried at $80{ }^{\circ} \mathrm{C}$ under vacuum in order to obtain an impurity free powder [11]. The surface area was $c a .130 \mathrm{~m}^{2} / \mathrm{g}$, measured by BET nitrogen adsorption method.

Characterizations. TEM analysis was monitored with a transmission electron microscope (JEOL $2000 \mathrm{FX}$ ) operating at an accelerating voltage of $200 \mathrm{kV}$. The XRD analysis was carried out on a Philips PW 1050 diffractometer with a Bragg Brentanon $\theta-2 \theta$. Cu anticathode under $40 \mathrm{kV}$ and $40 \mathrm{~mA}$. Granulometry measurements were performed with a mastersizer 2000 (Malvern Instruments). 
Lithium battery preparation. Electrochemical measurements were carried out by using conventional cells based on the "Li/liquid electrolyte/composite electrode". The anode was a large surface lithium metal foil (Aldrich 99.9\%). The liquid electrolyte was prepared by dissolving $1 \mathrm{M} \mathrm{LiClO}_{4}$ (Aldrich 99.99\%) in propylene carbonate solution (PC, Aldrich 99\%). The composite cathode was made by intimately mixing $71 \%$ (weight) of the active material (maghemite), 25\% of carbon "Ketjenblack" and 4\% PTFE. The carbon was used to insure the conductivity of the electrode and PTFE as ligand of both $\gamma-\mathrm{Fe}_{2} \mathrm{O}_{3}$ and carbon powders. The surface area of the cathode and mass of active material were adjusted to $1 \mathrm{~cm}^{2}$ and $20 \mathrm{mg}$ respectively for a better reproducibility. The electrode was dried under vacuum at $80^{\circ} \mathrm{C}$, for 3 hours, and introduced into an Argon-filled glove box for the cell assembly.

Electrochemical measurements. Galvanostatic chronopotentiometry measurements were performed using a computer-controlled potentiostat/galvanostat (Tacussel, PGS 201T model). Charge/discharge experiments were carried out in a galvanostatic mode at $8 \mathrm{~mA} / \mathrm{g}$ between 1.3 and $4.3 \mathrm{~V}$ vs. $\mathrm{Li}^{+} / \mathrm{Li}$. EIS was carried out by using a frequency response analyzer Solartron 1253 connected to a potentiostat PAR 273 (EGG Instrument). The high stability of the transient measurement did not require a signal treatment such as filter. The impedance diagrams were plotted at different open circuit voltages (OCVs) from the charged battery up to a complete discharged one. A constant voltage was first applied by the PAR 273 until the equilibrium state was reached, characterized by a zero current value. Then, the EIS measurements were performed in a frequency range between $20 \mathrm{kHz}$ and $1 \mathrm{mHz}$ with 8 points per decade and $20 \mathrm{mV}$ as AC amplitude to insure the linearity domain. 


\section{Results and discussion}

Characterization. The $\gamma-\mathrm{Fe}_{2} \mathrm{O}_{3}$ nanoparticles were synthesized and characterized by various techniques. The transmission electron microscopy (TEM) image of the sample (Fig. 2a) reveals elementary particles with relatively regular size of $c a .8-10 \mathrm{~nm}$, in agreement with the expected nanocrystalline structure of the pristine material. However, when the $\gamma-\mathrm{Fe}_{2} \mathrm{O}_{3}$ nanoparticles are precipitated and stocked in a dry state they tend to form larger aggregates. As an example, Fig. $2 \mathrm{~b}$ shows the aggregates formed when a dry powder of the starting material is grinded in conditions identical to those used for the preparation of the membrane for electrochemical measurements and redispersed in solution by sonication. Some of these aggregates can reach sizes as big as $400 \mathrm{~nm}$. These data were confirmed by a study by laser granulometry (Fig. 3), which shows the distribution of the particle size with a maximum centered at $300 \mathrm{~nm}$.

Quasi-equilibrium voltage measurements. These nanoparticles were studied by chronopotentiometry. Charge discharge curves at $\mathrm{C} / 25$ rate or $8 \mathrm{~mA} / \mathrm{g}$, within $1.3-4.3 \mathrm{~V}$ vs $\mathrm{Li}^{+} / \mathrm{Li}$ voltage range, are presented in Fig. 4. Below $1.0 \mathrm{~V}, \mathrm{Fe}_{2} \mathrm{O}_{3}$ is irreversibly reduced into $\mathrm{Fe}^{0}$ and $\mathrm{Li}_{2} \mathrm{O}$ [5]. At this slow rate, $1.5 \mathrm{Li}^{+}$per formula are inserted into the compound between the open-circuit voltage $(\mathrm{OCV}) \sim 2.8 \mathrm{Vvs} \mathrm{Li}^{+} / \mathrm{Li}$ and $1.3 \mathrm{~V}$, corresponding to a discharge capacity of $260 \mathrm{mAh} / \mathrm{g}$. The electrode is then charged from 1.3 to $4.3 \mathrm{~V}$ after this first discharge. A charge capacity of $c a .220 \mathrm{mAh} / \mathrm{g}$ is reached at the second cycle, for which $\sim 98 \%$ of the inserted lithium was desinserted. The capacity stabilizes with no more fading after the fifth cycle. This capacity retention capability is in striking contrast with the cycling performance of microcrystalline iron oxides and lithium iron oxides, [20, 21, 22, 23], which exhibit rapid capacity fading upon cycling. Phase transformations and structural irreversibility 
are the main reasons for the capacity fading of these and many other microcrystalline insertion compounds. More over, in [14], the authors reported a huge capacity fading upon cycling for their nanosized $\gamma-\mathrm{Fe}_{2} \mathrm{O}_{3}$, probably due to the too low anodic potential $(1.0 \mathrm{~V} v \mathrm{vs}$. $\mathrm{Li}^{+} / \mathrm{Li}$ ) used, which leads to the decomposition of the oxide as quoted in [5]. In the present work, the reversible capacity observed compares well with the $100 \mathrm{mAh} / \mathrm{g}$ obtained for layered $\mathrm{LiFeO}_{2}$ [24] and also with the theoretical capacity of $170 \mathrm{mAh} / \mathrm{g}$ for the lithium iron phosphate, $\mathrm{LiFePO}_{4}$ [25]. However, the electrochemical potential of $\gamma-\mathrm{Fe}_{2} \mathrm{O}_{3}$ is more than 1.0 V lower. Nevertheless, it is appropriate for electronic devices such as IC memory back up [9]. Equally, an interesting aspect is that large portions of the voltage curve of nano $\gamma-\mathrm{Fe}_{2} \mathrm{O}_{3}$ at this low current rate lie well above the equilibrium voltage curve of microcrystalline $\gamma-\mathrm{Fe}_{2} \mathrm{O}_{3}[3$, 14] and $\alpha-\mathrm{Fe}_{2} \mathrm{O}_{3}$ [8]. We will also note that the very first OCV of the material (2.8 V vs. $\left.\mathrm{Li}^{+} / \mathrm{Li}\right)$ is low as compared to the applied limit potential (4.3 $\left.\mathrm{Vvs.} \mathrm{Li}^{+} / \mathrm{Li}\right)$ assuming that some of the irons are already partially reduced (Fig. 4). Indeed, this as prepared nanosized $\gamma-\mathrm{Fe}_{2} \mathrm{O}_{3}$ has been shown to contain traces of $\mathrm{Fe}^{2+}$ on the grain surface, $[26,27]$ which then contribute to settle the initial $\mathrm{OCV}$ value down to $2.8 \mathrm{~V}$ vs. $\mathrm{Li}^{+} / \mathrm{Li}$. These surface $\mathrm{Fe}^{2+}$ species are oxidized into $\mathrm{Fe}^{3+}$ during the first charge between $2.8 \mathrm{~V}$ and $4.3 \mathrm{~V}$ vs. $\mathrm{Li}^{+} / \mathrm{Li}$, with anions from the electrolyte maintaining the electroneutrality. This surface oxidation of already present $\mathrm{Fe}^{2+}$ species fixes the initial potential of the second and following discharges at the high 4.3 V vs. $\mathrm{Li}^{+} / \mathrm{Li}$ value (Fig. 4).

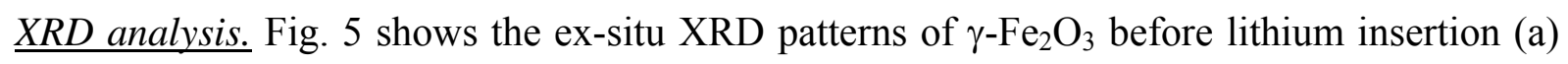
and after the initial discharge (b) to $1.3 \mathrm{~V}$ vs. $\mathrm{Li}^{+} / \mathrm{Li}$. Both patterns show poorly developed peaks, indicating short-range order, characteristic of the expected nanocrystalline structure. The comparison of the two patterns shows that the peaks of $\gamma-\mathrm{Fe}_{2} \mathrm{O}_{3}$ hardly changed after the discharge. Note that the nanoparticle size $(\sim 80 \AA)$ calculated from the full width at half 
maximum (FWHM) of the (311) diffraction peak using Scherrer equation corresponds well to that estimated by TEM (Fig. 2). We observed a slight shift of the XRD peaks towards low angles after the complete discharge to $1.3 \mathrm{~V}$. The lattice parameter changes from $8.35 \AA$ to $8.37 \AA$ and corresponds to an expansion of approximately $0.2 \%$, in agreement with [14]. Finally, Fig. 5 indicates that the downsizing of the $\gamma-\mathrm{Fe}_{2} \mathrm{O}_{3}$ particle is sufficient to lead to significant suppression of the well-known irreversible spinel-rocksalt transformation [2, 3].

EIS investigation. In Fig. 4, the different OCVs corresponding to the EIS investigation have been positioned on the discharge curve. Figs. 6 and 7 show the impedance diagrams in the Nyquist plan for different OCV values. In order to enhance the resolution of the graphs, the OCV domain between $3.5 \mathrm{~V}$ and $1.9 \mathrm{~V}$ vs. $\mathrm{Li}^{+} / \mathrm{Li}$ (Fig. 6) are detailed in Fig. 7. The curves shape similarity leads to identify the same electrochemical mechanism occurring during the whole discharged process. In the high frequency domain, a capacitive semi-circle was observed. This response was attributed to the $\mathrm{Fe}^{\mathrm{III}} / \mathrm{Fe}^{\mathrm{II}}$ redox process in the $\gamma-\mathrm{Fe}_{2} \mathrm{O}_{3}$ matrix. In the middle frequency range, the linear evolution with a $45^{\circ}$ slope angle (Fig. 7) is characteristic of the diffusion process of $\mathrm{Li}^{+}$in the electrode during the insertion-deinsertion. In the lowest frequency domain, the capacitive behaviour observed shows the characteristic response of a finite blocked diffusion. Therefore, and as expected, the discharge of the lithium battery is governed by a rapid and reversible process of $\mathrm{Fe}^{\mathrm{III}} / \mathrm{Fe}^{\mathrm{II}}$ oxydo-reduction involving a slower $\mathrm{Li}^{+}$diffusion in the electrode material to insure the electroneutrality. The first process can be depicted by a simple equivalent circuit which consists of a charge transfer resistance in parallel with a capacitive component called double layer capacity discussed below. The theoretical model of $\mathrm{Li}^{+}$diffusion process will be discussed afterwards.

(i) Charge transfer process - For the different OCV, the capacitive semi circles observed in the high frequency range (Fig. 8) were fitted using the equivalent circuit given in Fig. 9 
without the contribution of $Z_{W}$. The CPE (constant phase element) impedance was written as follows [28],

$$
Z_{C P E}=\frac{1}{Q(j \omega)^{\beta}}
$$

where $0<\beta<1$. Note that for a value of $\beta=1, Q$ directly corresponds to a capacity $C$.

The good agreement between the fitted and experimental curves in the high frequency-domain (Fig. 8) led the $R_{c t}$ and $Q$ values to be estimated. It has to be noticed that the $\beta$ value was maintained constant for the different $\mathrm{OCV}$ at a value of 0.87 . Fig. 10.a and $\mathrm{b}$ show the evolution of $Q$ and $R_{c t}$ with respect to the $\mathrm{Li}^{+}$amount inserted in the $\gamma-\mathrm{Fe}_{2} \mathrm{O}_{3}$ matrix. The $Q$ value was directly proportional to the capacity because of the constant $\beta$ value (Fig. 10a). It was shown that $Q$ decreased from a value of $7.9 \mu \mathrm{F} . \mathrm{s}^{(1-\beta)}$ when zero $\mathrm{Li}^{+}$ion was inserted down to $3.4 \mu \mathrm{Fs}^{(1-\beta)}$ corresponding to the discharged battery at $1.4 \mathrm{~V} v \mathrm{~s} . \mathrm{Li}^{+} / \mathrm{Li}$. As for the charge transfer process, the $R_{c t}$ value remained sensibly constant between $3.5 \mathrm{~V}$ and $2.6 \mathrm{~V} v s . \mathrm{Li}^{+} / \mathrm{Li}$ as applied potential. Then, below $2.6 \mathrm{~V}$ vs. $\mathrm{Li}^{+} / \mathrm{Li}$ this resistance drastically increases as the electrode potential decreases down to $1.3 \mathrm{~V} v s . \mathrm{Li}^{+} / \mathrm{Li}$. Different sizes of nanoparticles of $\gamma-$ $\mathrm{Fe}_{2} \mathrm{O}_{3}$ were synthesized and the experimental results concern the $8 \mathrm{~nm} \gamma-\mathrm{Fe}_{2} \mathrm{O}_{3}$ shown in Fig. 2 to 5 . However, a similar evolution of $R_{c t}$ and $Q$ values was observed for $2 \mathrm{~nm}$ and $4 \mathrm{~nm}$ particle sizes $\gamma-\mathrm{Fe}_{2} \mathrm{O}_{3}$ (not shown here). In order to analyse the whole frequency domain plotted in Figs. 6 and 7, the diffusion process of the $\mathrm{Li}^{+}$ion was investigated.

(ii) Diffusion process - The shape of the capacitive response plotted in the low frequency range was similar to that observed for other insertion materials which have a well known 
microstructure [29, 30, 31]. Different theoretical models were developed to understand the diffusion mechanisms and to reach the characteristic parameters involved in the insertion process. Two main approaches were considered. The first one consisted in using the transmission lines $[32,33]$. The second one was to derivate the diffusion equations in the case of a restricted diffusion such as $\mathrm{Li}^{+}$insertion $[34,35]$. If we consider a linear diffusion of a species in a plane sheet of thickness $L$ with an impermeable boundary, the well-known impedance equation of diffusion is written as follows,

$$
Z_{W}=\frac{\operatorname{coth}(j u)^{1 / 2}}{(j u)^{1 / 2}}
$$

where $u$ is the reduced frequency such as $u=\omega L^{2} / D$. $\omega$ is the angular frequency $(\omega=2 \pi f), f$ is the frequency. $D$ is the diffusion coefficient.

Eq. (2) leads to plot a $90^{\circ}$ as constant angle of the impedance in the low frequency domain of the Nyquist plan. However, the experimental data (Fig. 6) show a lower angle at the lowest frequencies. The classical restricted diffusion equation was not anymore appropriate to simulate the experimental impedance diagrams. Bisquert et al. [36, 37, 38] developed a dynamical model taking into account the roughness or porosity of the electrode material by using the impedance of the CPE (Eq. (3)) for the finite blocked diffusion.

$$
Z_{C P E}=\frac{1}{Q(j \omega)^{n}}
$$

where $\mathrm{Q}$ and $\mathrm{n}$ are the $\mathrm{CPE}$ prefactor and index respectively assumed to describe the interface between the electrolyte and the substrate. 
The equation consisted in adding two coefficients ( $\mathrm{n}$ and $\alpha$ ) in the restricted diffusion impedance to obtain a so called CPE-restricted diffusion process as according to eq. (4),

$$
Z_{W}=R_{W} \frac{\alpha(j u)^{n}+\sqrt{u} \operatorname{coth}(\sqrt{j u})}{j u+\alpha(j u)^{n+1 / 2} \operatorname{coth} \sqrt{j u}}
$$

with $u=\omega / \omega_{d}$ and $\omega_{d}=D / L^{2}$ where $\omega$ is the pulsation $\left(\mathrm{s}^{-1}\right), D$ is the diffusion coefficient of the lithium ion into the cathode and $L$ is the diffusion distance of $\mathrm{Li}^{+} . R_{W}$ is the diffusion resistance $(' \Omega)$.

$\alpha$ is the a dimensional parameter given by,

$$
\alpha=\frac{Q \omega_{d}^{n-1}}{C_{W}}
$$

with $0<\alpha<1$.

$\mathrm{C}_{\mathrm{W}}$ is the low frequency capacitance written as follows,

$$
C_{W}=\frac{L^{2}}{R_{W} D}
$$

Thus, the impedance $Z$ in the whole frequency domain taking into account the high frequency capacitive loop is written as follows,

$$
Z=R_{S}+\frac{Q\left(R_{c t}+Z_{W}\right)}{Q+\left(R_{c t}+Z_{W}\right) \omega^{(1-\beta)}\left(\sin \beta \frac{\pi}{2}+j \cos \beta \frac{\pi}{2}\right)}
$$


A good agreement between experimental and fitted data was observed for all OCVs using the equation (7), as illustrated in Fig. 11 for an $\mathrm{OCV}$ of $2.0 \mathrm{~V} v s . \mathrm{Li}^{+} / \mathrm{Li}$ leading to the different parameters of the impedance $Z$ with a good accuracy as shown in Fig. 12.

The four coefficients $n, \alpha, R_{W}$ and $\omega_{d}$ resulting from the fitting program using the simplex method are plotted with respect to the OCV in Fig. 12 a, b, c and d respectively. The $n$ value remains sensibly constant over the whole OCV range at a value similar to that obtained by Bisquert et al.[38]. In the case of fitted $\omega_{d}$, a sensibly constant value was observed for the discharged battery down to about $2.6 \mathrm{~V}$ vs. $\mathrm{Li}^{+} / \mathrm{Li}$ (Fig. 12d). For lower potential, this dimensionless time constant decreased continuously with decreasing OCV. If the distance $L$ is assumed to be constant, this last result shows that the diffusion coefficient of $\mathrm{Li}^{+}$decreased during the discharging process.

(iii) Discussion - In the case of nanosized particles as electrode material for $\mathrm{Li}^{+}$insertion, as shown in the introduction, a simplified band model has highlighted the reduction of all the external $\mathrm{Fe}^{\mathrm{III}}$ with specific $\mathrm{Li}^{+}$surface insertion phenomena at grain surface of the particles $[12,15,16]$. Indeed, the surface defects present in a nanocrystalline structure are a fundamental aspect to take into account in comparison with the microcrystalline homologues where the core effects are predominant. These surface defects as a part of structural ones, allow a solid-state solution behaviour with a small lattice parameter expansion $(0.2 \%)$. This strongly contrasts with the phase transition known for microcrystalline oxides. The two main electrochemical processes assumed by the model during the discharge of the nanocrystalline metallic oxide (during the $\mathrm{Li}^{+}$insertion process) were also detected by the EIS. In the high frequency range, the redox process of the couple $\mathrm{Fe}^{\mathrm{III}} / \mathrm{Fe}^{\mathrm{II}}$ was identified with the charge transfer resistance $R_{c t}$ and capacity values. A vertical line defined at $\sim 2.6 \mathrm{~V} v s$. $\mathrm{Li}^{+} / \mathrm{Li}$ was 
drawn in Fig. 10b in order to separate the discharging process in two domains. No significant variation of $R_{c t}$ was observed in the high potential domain (Fig. 10b) because the effect of surface defects is taking place with an equal accessibility of the active sites for reduction on the first atomic layers of the nanoparticles leading to the presence of sub-band gaps as proposed in Fig. 1. Such a surface reduction logically causes the abrupt decrease of the electrode potential from $4.3 \mathrm{~V}$ to $\sim 2.6 \mathrm{~V} v s . \mathrm{Li}^{+} / \mathrm{Li}$ (Fig. 4). After the reduction of the outer $\mathrm{Fe}^{\mathrm{III}}$, the insertion process continues by the reduction of the $\mathrm{Fe}^{\mathrm{III}}$ sites located deeper in the core of the nanoparticle. This second step is highlighted by a smoother decrease of the potential (Fig. 4); it corresponds to the continuous increase of $R_{c t}$ denoting a more difficult charge transfer process as the electrode potential decreases below $\sim 2.6 \mathrm{~V}$ vs. $\mathrm{Li}^{+} / \mathrm{Li}$. The accessibility and the number of the active sites for reduction are more and more reduced. Note that an enhancement of $R_{c t}$ during the $\mathrm{Li}^{+}$insertion process was already shown by $\mathrm{H}$. Li et al. using $\mathrm{SnO}$ as micro- and nano- insertion material.[39] This value of OCV of $2.6 \mathrm{~V} v s . \mathrm{Li}^{+} / \mathrm{Li}$ seems to be a key point for the dramatic change of behaviour of all the parameters as illustrated by the determination and evolution of $Q$ when the high frequency response of EIS is fitted (Fig. 10a). The percentage of dispersion of the nanoparticles in the membrane used as the cathode was not experimentally reachable, leading to an unknown value of the active surface. Consequently, the $Q$ value was not converted in surface units. However, above this value of $\mathrm{OCV}$ of $2.6 \mathrm{~V}$ vs. $\mathrm{Li}^{+} / \mathrm{Li}, Q$ was sensibly constant whereas a rapid decrease was observed below this value. The capacity $C$ which is directly proportional to the $Q$ coefficient, was written as follows,

$$
C=\frac{\varepsilon \varepsilon_{0} S}{d}
$$


where $\varepsilon$ is the real part of the permittivity of the active interface, $\varepsilon_{0}$ the permittivity of vacuum $\left(\varepsilon_{0}=9.10^{-14} \mathrm{~F} \cdot \mathrm{cm}^{-1}\right), S$ and $d$ the surface and the thickness of the interface respectively.

As the charge transfer process was assumed to occur in two steps, the first one at the surface of the nanosized material and the second step deeper in the core of the $\gamma-\mathrm{Fe}_{2} \mathrm{O}_{3}$ matrix, the measured capacity by EIS was not connected to the classical double layer capacitance $C_{d}$. Indeed, $C_{d}$ is typically measured in the presence of a conductive substrate / electrolyte interface. In the case of the experimental results presented in this paper, the decrease of the $Q$ value is probably due to the variation of the surface area where the redox process of $\mathrm{Fe}^{\mathrm{III}}$ took place. $Q$ decreased smoothly during the surface $\mathrm{Li}$ insertion process (down to $2.6 \mathrm{~V} v \mathrm{~s}$. $\mathrm{Li}^{+} / \mathrm{Li}$ ) corresponding to the progressive reduction of $\mathrm{Fe}^{\mathrm{III}}$ on the outer edge of the particle. Then, the $\mathrm{Li}^{+}$insertion in the core of the nanospheres induced a variation of the reactive surface area, generating the decrease of $Q$. When the electrode potential reached a value $\sim 1.5 \mathrm{Vvs} . \mathrm{Li}^{+} / \mathrm{Li}$, a lower $Q$ limiting value was observed (Fig. 10a). At this point, the HF of the EIS investigation highlights the existence of a transition between two physical mechanisms by using a classical redox process as theoretical model. The same HF process occurrs during both surface and core insertion mechanisms. This transition is characterised by a modification of $R_{c t}$ and $Q$ fitted values.

The low frequency domain of the fitted impedance spectra illustrated the restricted diffusion process of lithium ions. It is shown in Fig. $12 \mathrm{~d}$ that $\omega_{d}$ started decreasing for applied OCV lower than $2.6 \mathrm{~V} v$ s. $\mathrm{Li}^{+} / \mathrm{Li}$ corresponding to the same transition value found with the high frequency response.

At an OCV of $2.2 \mathrm{~V} v s . \mathrm{Li}^{+} / \mathrm{Li}$, a value of $\omega_{d} \cong 5.10^{-1} \mathrm{~s}^{-1}\left(\omega_{d}=D / L^{2}\right)$ was found. In a first approach, if the distance of $\mathrm{Li}^{+}$is assumed to be the radius of an 8-nm diameter nanoparticle, the diffusion coefficient of $\mathrm{Li}^{+}$is $\mathrm{D}_{\mathrm{Li}}^{+} \cong 310^{-13} \mathrm{~cm}^{2} \cdot \mathrm{s}^{-1}$ which seems too small to be 
considered as reasonable. On the other hand, if the distance $L$ is the total thickness of the material membrane, i.e. about $300 \mu \mathrm{m}, \mathrm{D}_{\mathrm{Li}}^{+} \cong 510^{-4} \mathrm{~cm}^{2} \cdot \mathrm{s}^{-1}$ becomes too high to be in agreement with the literature. In fact, the TEM images as well as the granulometry measurements showed that the dispersed colloidal $\gamma-\mathrm{Fe}_{2} \mathrm{O}_{3}$ particles (Figs. 2 and 3) form small aggregates with an estimated average diameter centred on $300 \mathrm{~nm}$ when grinded for electrode material preparation. Thus, this aggregate size leads to a diffusion coefficient of $\mathrm{D}_{\mathrm{Li}}{ }^{+} \cong 510^{-10}$ $\mathrm{cm}^{2} . \mathrm{s}^{-1}$ which is in agreement with data given in a previous paper.[40] This evidences the fact that the lithium insertion occurred in an aggregate of nanoparticles as elementary entity. Fig. 13 shows the variation of $\mathrm{D}_{\mathrm{Li}}{ }^{+}$with respect to $\mathrm{OCV}$. Once more the $2.6 \mathrm{~V}$ vs. $\mathrm{Li}^{+} / \mathrm{Li}$ as OCV seems to be a determining value. During the surface Li insertion process down to this value to 2.6 $\mathrm{V}$ vs. $\mathrm{Li}^{+} / \mathrm{Li}$ as previously shown, the diffusion coefficient remains approximately constant, as expected for a surface mechanism $[12,15,16]$. For lower potentials, the diffusion coefficient decreases corresponding to the more difficult insertion process deeper in the material as already shown for microcrystalline materials in the whole potential domain where the surface effects are negligible [29, 35, 40, 41]. So, the low frequency response of the EIS investigation reinforced the existence of a transition potential between the two surface and core insertion mechanisms.

Thus, during the "surface" process, sensibly constant values of $\mathrm{R}_{\mathrm{ct}}, \mathrm{Q}$ and $\mathrm{D}_{\mathrm{Li}}{ }^{+}$were measured from EIS investigation denoting the free accessibility of the reduction sites at the surface of the nanoparticles. Then, in a second step corresponding to the insertion process in the core of the particle, $\mathrm{Q}$ and $\mathrm{D}_{\mathrm{Li}}{ }^{+}$decreased whereas $\mathrm{R}_{\mathrm{ct}}$ increased, in agreement with microcrystalline insertion materials where the first step is not predominant.

It has to be noticed that $\alpha$ (Fig. 12b), which is the other correction coefficient introduced by Bisquert et al, $[36,37,38]$, strongly decreased from 0.25 to 0.1 when the OCV value was 
lower than $1.8 \mathrm{~V}$ vs. $\mathrm{Li}^{+} / \mathrm{Li}$ corresponding to a lower limit value than the $2.6 \mathrm{~V}$ vs. $\mathrm{Li}^{+} / \mathrm{Li}$ characterizing the transition between surface and core insertions in the nanoparticle. In Fig. $12 \mathrm{c}$, the variation of the resistance $R_{W}$, which is a characteristic parameter of the $\mathrm{Li}^{+}$diffusion process, shows as well an OCV limit value, as for the evolution of $\alpha$. A constant $R_{W}$ was found for $\mathrm{OCV} \geq 1.8 \mathrm{~V}$ vs. $\mathrm{Li}^{+} / \mathrm{Li}$ (Fig. $12 \mathrm{c}$ ). For lower potential, the diffusion resistance drastically increases as OCV decreases down to $1.3 \mathrm{~V} v$ s. $\mathrm{Li}^{+} / \mathrm{Li}$, corresponding to $\approx 1.4 \mathrm{Li}^{+}$ inserted in the electrode material (Fig. 4). This can be explained considering the structure of $\gamma-\mathrm{Fe}_{2} \mathrm{O}_{3}$. It is an inverse spinel-like structure with cubic closed-packed array of anions, the $\mathrm{Fe}^{\mathrm{III}}$ being located in both tetrahedral and octahedral sites. In each unit cell, 32 octahedral and 64 tetrahedral sites are available for occupation by cations. Out of these, 16 octahedral and 8 tetrahedral sites are occupied by $\mathrm{Fe}^{\mathrm{III}}$ in a regular manner. When a microcrystalline $\gamma-\mathrm{Fe}_{2} \mathrm{O}_{3}$ is used as electrode material, a phase transition from spinel to cubic rock-salt structure occurs when $\mathrm{Li}^{+}$ions progressively fill the empty remaining octahedral sites generating coulombic interactions with their closest iron neighbours situated in tetrahedral sites. While this phase transition does not take place any more in the nanocrystalline material because of the possibility of a higher lattice expansion in nanostructures as compared to bulk compounds, the electrostatic interactions still remain and are probably responsible for this increase of $R_{W}$ and the variation of $\alpha$.

\section{Conclusion}

We have reported the synthesis, characterizations, electrochemical study and impedance spectroscopy of a nanocrystalline $\gamma-\mathrm{Fe}_{2} \mathrm{O}_{3}$. This nanomaterial exhibits simultaneously a very high lithium capacity and good capacity retention upon cycling. These properties reveal thermodynamics of the nanocrystalline material which are definitely different from those of 
its microcrystalline analogue. The EIS have shown that the electrochemical insertion of the lithium ion occurs according to two mechanisms involving : first the reduction of the surface $\mathrm{Fe}^{3+}$, with the "physical grafting" of $\mathrm{Li}^{+}$on to the surface defects of the nanoparticles and then the reduction of the core $\mathrm{Fe}^{3+}$ with the insertion of the $\mathrm{Li}^{+}$deeper in the particle.

The transition between the two mechanisms was identified by a change of the physical parameters fitted by means of a classical electrochemical model used for microcrystalline insertion material. The surface process is not an additional one involved in the electrochemical model. Indeed, an additional one would be characterised by an extra time constant in impedance diagrams as shown by Thomas et al. [42] in the case of the adsorption of $\mathrm{Li}^{+}$onto the electrode surface. The determination of the different EIS parameters led to the determination of the $\mathrm{Li}^{+}$diffusion coefficient which is in good agreement with the motion of $\mathrm{Li}^{+}$in nano-aggregates $(300 \mathrm{~nm})$ made of elementary $\gamma-\mathrm{Fe}_{2} \mathrm{O}_{3}$ nanoparticles $(8 \mathrm{~nm}$ diameter). These results confirm the promising properties of such nanostructured insertion compounds as electrodes for low-voltage rechargeable lithium batteries.

\section{Acknowledgments :}

We are grateful to Dr. L. Croguennec and P. Gravereau for helpful discussions. S. Pechev and P. Dagault are acknowledged for X Ray diffraction assistance. This work was partly supported by the CNRS and the Conseil Régional d'Aquitaine. 


\section{Figure caption}

Figure 1. Schematic band model differentiating the surface (1) and core (2) lithium insertion processes for nanocrystalline materials.

Figure 2. a) TEM micrograph of pristine maghemite $\gamma-\mathrm{Fe}_{2} \mathrm{O}_{3}$ nanoparticles. b) TEM micrograph of maghemite $\gamma-\mathrm{Fe}_{2} \mathrm{O}_{3}$ aggregates obtained after precipitation, drying and redispersion in water solution.

Figure 3. Granulometry of maghemite $\gamma-\mathrm{Fe}_{2} \mathrm{O}_{3}$ aggregates obtained after precipitation, drying and redispersion in water solution.

Figure 4. Discharge-charge curves of the five first cycles of nanocrystalline $\gamma-\mathrm{Fe}_{2} \mathrm{O}_{3}$ at 8 $\mathrm{mA} / \mathrm{g}(\mathrm{ca} \mathrm{C} / 25)$ between 1.3 and $4.3 \mathrm{~V}$ vs. $\mathrm{Li}^{+} / \mathrm{Li}$. The numbers in brackets locate the OCV used for the EIS investigation.

Figure 5. Ex-situ XRD patterns of the $\gamma-\mathrm{Fe}_{2} \mathrm{O}_{3}$ electrode material (a) of the as-synthesized pristine $\gamma-\mathrm{Fe}_{2} \mathrm{O}_{3}$ (b) after the first discharge to $1.3 \mathrm{~V} v$ s. $\mathrm{Li}^{+} / \mathrm{Li}$.

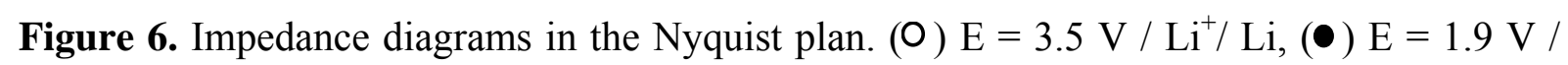
$\mathrm{Li}^{+} / \mathrm{Li},(\Delta) \mathrm{E}=1.7 \mathrm{~V} / \mathrm{Li}^{+} / \mathrm{Li},(\Delta) \mathrm{E}=1.5 \mathrm{~V} / \mathrm{Li}^{+} / \mathrm{Li},(\square) \mathrm{E}=1.4 \mathrm{~V} / \mathrm{Li}^{+} / \mathrm{Li}$.

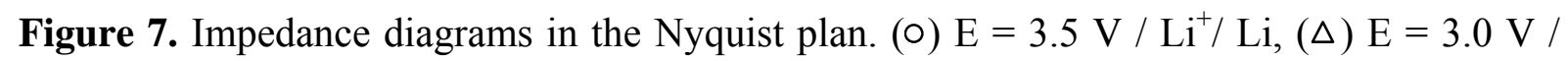
$\mathrm{Li}^{+} / \mathrm{Li},(\bullet) \mathrm{E}=2.6 \mathrm{~V} / \mathrm{Li}^{+} / \mathrm{Li},(\bullet) \mathrm{E}=1.9 \mathrm{~V} / \mathrm{Li}^{+} / \mathrm{Li}$.

Figure 8. High frequency response of the impedance diagrams in the Nyquist plan. $(\bullet) \mathrm{E}=3.5 \mathrm{~V} / \mathrm{Li}^{+} / \mathrm{Li},(\diamond) \mathrm{E}=3 \mathrm{~V} / \mathrm{Li}^{+} / \mathrm{Li},(\bullet) \mathrm{E}=2.6 \mathrm{~V} / \mathrm{Li}^{+} / \mathrm{Li},\left(\right.$ () $\mathrm{E}=1.9 \mathrm{~V} / \mathrm{Li}^{+} / \mathrm{Li}$, (४) $\mathrm{E}=1.7 \mathrm{~V} / \mathrm{Li}^{+} / \mathrm{Li},(\Delta) \mathrm{E}=1.5 \mathrm{~V} / \mathrm{Li}^{+} / \mathrm{Li},(\bullet) \mathrm{E}=1.4 \mathrm{~V} / \mathrm{Li}^{+} / \mathrm{Li}$. (×) fitted diagrams using the equivalent circuit in Fig. 9 without the contribution of $Z_{W}$.

Figure 9. Equivalent circuit of the electrochemical impedance spectra. $R_{e}$ : electrolyte resistance, $R_{c t}$ : charge transfer resistance and CPE: constant phase element. $Z_{W}$ is the CPErestricted diffusion given by eq. (4). 
Figure 10. $Q$ and $R_{c t}$ values versus OCV. The data were fitted parameters using the equivalent circuit in Fig. 9 without the contribution of $Z_{W}$.

Figure 11. Impedance diagrams in the Nyquist plan. ( $\bullet$ ) experimental and $(\Delta)$ fitted diagram using the equation (7). $R_{S}=27 \Omega, R_{t c}=29 \Omega, Q=4.5 \mu \mathrm{F} . \mathrm{s}^{(1-\beta)}, \beta=0.13, n=0.52, \alpha=0.22$, $\omega_{d}=5.10^{-1} \mathrm{~s}^{-1}, R_{W}=37.5 \Omega$.

Figure 12. $n, \alpha, R_{W}$ and $\omega_{d}$ values versus OCV. The data were fitted parameters using the Eq. (7).

Figure 13. Variation of the $\mathrm{Li}^{+}$diffusion coefficient with the OCV potential. 


\section{References}

1 M. M. Thackeray, W. I. F. David, J. B. Goodenough, Mater. Res. Bull. 17 (1982) 785.

2 M. Pernet, J. Rodriguez, M. Gonderand, J. Fontcuberta, P. Strobel, J.C. Joubert, in: Proceedings of ICF-5, 1989, India.

3 B. Bonnet, P. Strobrl, M. Pernet, M. Gondrand, Y. Gros, Mater. Sci. Forum 91-93 (1992) 345.

4 D. Larcher, C. Masquelier, D. Bonnin, Y. Chabre, V. Masson, J. B.Leriche, J. -M. Tarascon, J. Electrochem. Soc. 150 (2003) A133.

5 D. Larcher, D. Bonnin, R. Cortes, I. Rivals, L. Personnaz, J. -M. Tarascon, J. Electrochem. Soc. 150 (2003) A1643.

6 T. Matsumura, N. Sonoyama, R. Kanno, M. Takano, Solid State Ionics 158 (2003) 253.

7 a) S. Ito, K. Ui, N. Koura, K. Akashi, Solid State Ionics 113-115 (1998) 17. b) S. Ito, T. Aoyama, K. Akashi, Solid State Ionics 113-115 (1998) 23.

8 a) G. Jain, C. J. Capozzi, J. J. Xu, J. Electrochem. Soc. 150 (2003) A806. b) J. J. Xu, G. Jain, Electrochem. Solid-State Let. 6 (2003) A190.

9 S. Komaba, K. Suzuki, N. Kumagai, Electrochemistry 70 (2002) 506.

10 C. W. Kwon, A. Poquet, S. Mornet, G. Campet, J. Portier, J.H Choy. Electrochem. Commun. 4 (2002) 197.

11 C. W. Kwon, A. Poquet, N. Treuil, J. Portier, J. H. Choy, G. Campet, in New trends in Intercalation Compounds for Energy Storage, Ed. C. Julien, J. P. Pereira-Ramos, A. Momchilov, Kluwer Academic publishers, Netherlands (2002).

12 G. Campet, S. J. Wen, S. D. Han, M. Shastry, J. Portier, C. Guizard, L. Cot, Y. J. Xu, J. Salardenne, Materials Science and Engineering B 18, (1993) 201.

13 C. W. Kwon, M. Quintin, S. Mornet, C. Barbieri, O. Devos, G. Campet, and M. H. Delville, Journal of The Electrochemical Society 151 (2004) A1445. 
14 S. Kanzaki, T. Inada, T. Matsumura, N. Sonoyama, A. Yamada, M. Takano, R. Kanno, J. Power Sources 146 (2005) 323.

15 M. Quintin, A. V. Murugan, C. W. Kwon, O. Devos, M. H. Delville, H. S. Hilal, and G. Campet In Electrochemical Studies of Batteries. ed. M. Nunez. Hauppauge (N. Y.): Nova Science Publishers, 2005. p. 115-146. ISBN 1-59454-329-1

16 a) G. Campet, B. Morel, J. Portier, C. Delmas, M. Bourrel, J. Salardenne, Materials Science and Engineering B 8 (1991) 303; b) C. Brigouleix, P. Topart, E. Bruneton, F. Sabary, G. Nouhaut, G. Campet, Electrochim. Acta, 46 (2001) 1931.

17 N. Treuil, C. Labrugère, M. Menetrier, J. Portier, G. Campet, A. Deshayes, J. C. Frison, S. J. Hwang, S.W. Song, J. H. Choy, J. Phys. Chem. B 103 (1999) 2100; c) J. H Choy, Y. I. Kim, G. Campet, J. Portier P. V. Huong, J. Solid State Chem. 142 (1999) 368.

18 R. Massart, IEEE Trans. Magn. 17 (1981) 1247.

19 R. Massart, S. Neveu, V. Cabuil-Marchal, R. Brossel, J. M. Fruchart, T. Bouchami, J. Roger, A. Bee-Debras, J. N. Pons, M. Carpentier, French Patent 1990, No. 2662539.

20 R. Kanno, T. Shirane, Y. Kawamoto, Y. Takeda, M. Takano, M. Ohashi, and Y. Yamaguchi, J. Electrochem. Soc. 143 (1996) 2435.

21 K. M. Abraham, D. M. Pasquariello, E. B. Willstaedt, J. Electrochem. Soc. 137 (1990) 743.

22 X. Wu, S. Kim, Electrochem. Solid-State Lett. 2 (1999) 184.

23 S. Morzilli, B. Scrosati, Electrochim. Acta 30 (1985) 1271.

24 P. P. Prosini, M. Carewska, S. Loreti, C. Minarini S. Passerini, Int. J. Inorg.Mater. 2 (2000) 365 .

25 A. K. Padhi, K. S. Najundaswamy, J. B. Goodenough, J. Electrochem. Soc. 144 (1997) 1188.

26 C. T. Wang, S. H. Ro, J. Non-Crystalline Solids, 352 (2006) 35. 
27 B. M. Weckhuysen, D. Wang, M. P. Rosynek, J. H. Lunsford, J. Catal. 175 (1998) 347.

28 G.J. Brug, A.L.G. Van Den Eeden, M. Sluyters-Rehbach, J.H. Sluyters, J. Electroanal. Chem. 176 (1984) 275.

29 Y. - M Choi, S. -I Pyun, S. -I Moon, Y. -E Hyung, J. Power Sources 72 (1998) 83

30 A. -K Hjelm, G. Lindbergh, Electrochim. Acta 47 (2002) 1747.

31 E. Barsoukov, D. -H. Kim, H. -S. Lee, H. Lee, M. Yakovleva, Y. Gao, J. F. Engel, Solid State Ionics 161 (2003) 19.

32 M. D. Levi, D. Aurbach, J. Phys. Chem. B 101 (1997) 4630.

33 F. Fabregat-Santiago, G. Garcia-Belmonte, J. Bisquert, A. Zaban, P. Salvador, J. Phys. Chem. B 106 (2002) 334.

34 T. Jacobsen, K. West, Electrochim. Acta 40 (1995) 255.

35 R. Cabanel, G. Barral, J. -P Diard, B. Le Gorrec, C. Montella, J. Applied Electrochem. 23 (1993) 93.

36 J. Bisquert, G. Garcia-Belmonte, F. Fabregat-Santiago, P. R. Bueno, J. Electroanal. Chem. 475 (1999) 152.

37 J. Bisquert, G. Garcia-Belmonte. P. Bueno, E. Longo, L. O. S. Bulhoes, J. Electroanal. Chem. 452 (1998) 229.

38 F. Fabregat-Santiago, G. Garcia-Belmonte, J. Bisquert, N. S. Ferriols, P. R. Bueno, E. Longo, J. S. Anton, S. Castro-Garcia, J. Electrochem. Soc. 148 (2001) E302.

39 H. Li, X. Huang, L. Chen, J. Power Sources 81-82 (1999) 340.

40 S. I. Pyun, J. S. Bae, Electrochim. Acta 41 (1996) 919.

41 S. -I. Pyun, Y. -G. Ryu, J. Power Sources 70 (1998) 34.

42 M. G. S. R. Thomas, P. G. Bruce, J. B. Goodenough, J. Electrochem. Soc. 132 (1985) 1521. 